\title{
El uso de las tics en la promoción y análisis del discurso oral en el aula
}

Yolima Gutiérrez Ríos'

yolimagr@yahoo.es

\section{RESUMEN}

Este artículo presenta algunos resultados de una investigación que actualmente se lleva a cabo con los estudiantes de educación media de la Normal Superior Distrital María Montessori (Localidad 15, Bogotá D.C.) en las clases de Lengua Castellana e Informática. El objetivo de esta experiencia es estudiar cómo inciden las Tecnologías de la Información y la Comunicación (TICS) en el fortalecimiento del discurso oral. Los resultados de esta experiencia pedagógica e investigativa dan cuenta de la necesidad de pensar cómo se incorpora el discurso oral en el currículo y en las actividades del aula.

\section{Palabras clave}

Discurso oral, $A C D$, enseñanza, aprendizaje, investigación, Tics, blogs.

\section{ABSTRACT}

This article presents some of the results of the research currently being carried out through with high school students at the Normal Superior Distrital María Montessori (15th District-Village, Bogotá D.C.) in the Spanish Language and Computer classes. The purpose of this experience is to study how the Technologies of the Information and Communication (TICS) influence the strengthening of the oral discourse. The results of this pedagogical experience and research work point out the absolute necessity to think how to incorporate the oral discourse in the curriculum and in classroom activities.

\section{KEYWORDS}

Oral speech, ACD, teaching, learning, investigation, TICS, blogs.

Escuela Normal Superior Distrital María Montessori-Universidad Distrital Francisco José de Caldas. Profesora de Lengua Castellana y Literatura. Estudiante del Doctorado Interinstitucional en Educación con Énfasis en Lenguaje, Universidad Distrital Francisco José de Caldas. Miembro del grupo de investigación Lenguaje, Identidad y Cultura. 


\section{Introducción}

$\mathrm{N}$ os encontramos ante la presència de una revolución tecnológica propia de la sociedad globalizada en que vivimos, cuya demanda implica establecer una relación sinérgica entre el mundo de las nuevas comunicaciones y la escuela, dos contextos aparentemente articulados en la dinámica social pero muy distantes en los usos y reflexiones relacionados con las herramientas de la tecnología digital. Si bien los dispositivos tecnológicos han ingresado abruptamente al contexto escolar, también han sido incorporados en algunos campos del saber con pocos cuestionamientos sobre su uso y sus implicaciones pedagógicas y didácticas, en tanto su pretensión es dialogar con nuevas formas de aprendizaje con el fin de garantizar, entre otros, la indagación, interacción y construcción de nuevos conocimientos en ambientes comunicativos y polisémicos. Contreras (2005) plantea al respecto que uno de los problemas fundamentales de la revolución tecnológica y la globalización es la manipulación de series y redes sumamente heterogéneas que impactan social y culturalmente a las nuevas generaciones predisponiéndolas a una discontinuidad lingüística.

Parto de la consideración de entender la presencia de las tecnologías en la escuela como una situación limítrofe que puede ser positiva o que puede ser de otro orden, en tanto no se reconozca la necesidad de ciertas orientaciones de carácter cultural, político, ético y económico con miras a comprender sus repercusiones en la sociedad contemporánea y, particularmente, en las presentes generaciones. En principio y desde nuestro rol de maestros tenemos la posibilidad de anticiparnos a esa cultura emergente o, por lo menos, de estar atentos a orientar su incorporación y posibles implicaciones desde una perspectiva crítica que desnaturalice prácticas, rutinas, estereotipos, con miras a transitar hacia zonas de diferencia cultural desde $y$ con las nuevas posibilidades que ofrecen las tecnologías y a encontrar otras formas de hablar y de habitar el mundo haciendo resistencia crítica a sistemas y discursos totalizadores y hegemónicos.

También considero que el auge de nuevas prácticas comunicativas mediadas por el chat, el correo electrónico, el blog, el foro y diversas fuentes de información como las bibliotecas virtuales, portales especializados, prensa digital y un sinnúmero de posibilidades mediáticas, tan usadas por los niños y jóvenes de hoy, pueden constituirse en un complemento-natural para el desarrollo de nuevas formas de aprendizaje $y$, particularmente, para enriquecer la enseñanza de la oralidad, la lectura y la escritura como modalidades del lenguaje y prácticas sociales de los sujetos.

Urge, entonces, que maestros y estudiantes construyamos un espacio común de interlocución en torno a las Tecnologías de la Información y la Comunicación (TICS) $)^{2}$ y que encontremos caminos alternativos para la construcción de conocimiento desde un uso ético y una visión prospectiva sobre su impacto a nivel académico, social y cultural. Estas reflexiones condujeron a plantear la propuesta de incorporar herramientas tecnológicas en la clase de Lengua Castellana para construir nuevos escenarios, roles y géneros discursivos orientados a fortalecer la producción oral de los estudiantes.

Dada la complejidad para estudiar la oralidad en sus diferentes dimensiones y las casi inexistentes experiencias investigativas en relación con su enseñanza y aprendizaje en

\footnotetext{
2 Definidas como instrumentos y procesos utilizados para recuperar, almacenar, organizar, manejar, producir, presentar e intercambiar información por medios electrónicos y automáticos. Por ejemplo: los equipos físicos y programas informáticos, material de telecomunicaciones en forma de computadoras personales, escáners, cámaras digitales, asistentes personales digitales, teléfonos, facsímiles, módems, tocadiscos, grabadoras de $\mathrm{CD}$ y DVD, radio y televisión, además de programas como bases de datos y aplicaciones multimedia. En resumen, las TICs son aquellas tecnologías que permiten transmitir, procesar y difundir información de manera instantánea (http://www.etic.bo/Capitulo1/TIC.htm).
} 
la educación secundaria, nos proponemos aquí realizar un estudio preliminar que nos permita caracterizar el discurso de los blogs y aplicar algunas categorías analíticas para acercarnos a su comprensión. Así, pues, surgen las preguntas por ¿cómo implementar las TICs como dispositivos que coadyuven en el fortalecimiento del discurso oral de los estudiantes de educación media? y ¿qué categorías pueden orientar el análisis del discurso oral en los blogs?

\section{Presupuestos teóricos}

Es importante empezar por reconocer el impacto que generan la información y la comunicación, como ámbitos de las Tics, en los procesos de enseñanza y aprendizaje: de una parte, se evidencia la coexistencia de modos de vida, creencias, tradiciones y actividades con las dinámicas de las nuevas tecnologías, situación que repercute en el modo como las estructuras mentales organizan e interpretan la información. Esto implica un cambio en la cultura académica y en particular en la construcción de conocimiento. De otra parte, ante la presencia de redes de tecnologías, sin duda estamos frente a un soporte electrónico con otro tipo de textos, de fuentes de información y de nuevos procesos cognitivos traslapados en los modos de leer, escribir, incluso de hablar y escuchar. En este proceso se evidencia un cambio en la relación con el espacio, el tiempo y el lugar. No es igual situarnos en un cronotopos "real" que en uno "mediático", donde cambia la representación del aquí, del ahora y de la construcción de universos de sentido. Por esto, es fundamental reflexionar sobre los procesos cognitivos de los estudiantes cuando interactúan a través del soporte informático en el marco de situaciones didácticas (Rueda Ortiz, 1999 y Jonassen, Strobel y Gottdenker, 2005, citados en: Perelman et al., 2007).

De este modo, el uso de entornos virtuales (como los blogs) en situaciones de ensènanzaaprendizaje va más allá de constituirse en una estrategia metodológica: se trata de la incorporación de nuevas formas de interacción, de enseñar y aprender de manera colaborativa $y$; sobre todo, de construir una nueva identidad personal, o como lo plantea Rueda: la reflexión sobre los entornos de interacción y comunicación virtual debe ser contenido mismo de la pedagogía, en tanto ésta se debe preguntar por el tipo de subjetividades que forma en dichos entornos virtuales (chats, blogs, foros, juegos de roles, etc.) y que transforman no solo las nociones de sujeto, sino las maneras de producir conocimiento, adquirir experiencia y participar. como ciudadanas y ciudadanos en el escenario simbólico contemporáneo (2007: 160).

La comunicación electrónica ha ido constituyendo nuevas comunidades discursivas conformadas por internautas, quienes a un ritmo vertiginoso han logrado construir una cultura omnipresente, que șin duda transforma las prácticas lectoras y escritoras. "cotidianas" en nuevas prácticas discursivas denominadas por Cassany "nueva literacidad". ${ }^{3}$ Cassany advierte que la literacidad se ha asociado tradicionalmente a la capacidad de leer y escribir textos manuscritos o impresos desde una perspectiva social que abarca todos los conocimientos y actitudes necesarios para su uso eficaz en una comunidad de los géneros escritos. Sin embargo:

La literacidad no incluye sólo lo escrito. Hoy accedemos a muchos discursos a través de la oralidad, que se han planificado previamente con la escritura. Es el caso de la televisión y la radio o de muchas charlas e intervenciones orales. Sólo tienen envoltorio acústico: su concepción y organización fueron totalmente planificadas, meditadas, o sea, escritas. También integramos la escritura con el habla y la imagen en otros discursos; como presentaciones con transparencias, webs o vídeo. Todo cabe en la literacidad (2006: 40).

En efecto, la oralidad ${ }^{4}$ está en la escritura y se nutre de sus logros y la escritura está en

\footnotetext{
Literacidad viene del término anglosajón literacy, que significa lectoescritura o alfabetización; en francés se denomina lettrisme y en español se propuso escrituralidad, como oposición a la oralidad (Cassany, 2006).

4 Es importante anotar que el término oralidad es de uso relativamente reciente en los estudios sobre lenguaje. Comienza a utilizarse en el siglo $\mathrm{xx}$ y se extiende a
} 
la oralidad y se apoya en ella, porque la relación entre ambas no es de oposición sino de complementariedad y de coexistencia en una dimensión discursiva que suscita emociones, generà interlocuciones, orienta el pensamiento y convoca a la acción. Así lo señala Rodríguez: "la modalidad escrita y la oralidad son prácticas sociales que integran diversas funciones de la actividad humana, dentro de las cuales destacamos la cognitiva, la intersubjetiva y la cultural" (2006: 60). No obstante, estas modalidades discursivas se definen y caracterizan de manera independiente, con la pretensión de establecer ciertos límites de carácter epistemológico y metodológico.

Así, la modalidad oral es una realización de la lengua y una forma de significar un ámbito específico del accionar social, de hecho hace posible las relaciones entre los sujetos, generando una interlocución o acción conjunta. Jaimes habla de reciprocidad y mutualidad: "La reciprocidad hace referencia a la conciencia de que lo que hace cada una de las partes suscita la acción discursiva de la otra y establece un sistema de relaciones mutuas. La mutualidad, la más esencial, supone la necesidad de las partes para operar discursivamente" (2003: 23).

El discurso oral es considerado, entonces, como una práctica social concreta, muy significativa por su carácter de construcción social y muy usual en las actividades personales e institucionales que desarrollan las comunidades. En el sentido en que lo plantea Abascal:

El proceso y producto de la oralidad es el discurso oral, el cual presenta una gran variedad. En sus formas más prototípicas, se configura mediante la intervención de todos los elementos señalados (la conversación familiar o el sermón en la iglesia, por ejemplo, responden a estos parámetros y constituyen for-

\footnotetext{
partir de los años 60 en virtud de investigaciones que, desde perspectivas disciplinarias diversas, subrayan la oposición entre oralidad y escritura. Desde entonces ha ido en aumento el interés de los investigadores por el estudio de la comunicación oral y el término oralidad se ha ido filtrando de manera natural, aunque a veces con un sentido teórico difuso, en el vocabulario de quienes se ocupan de tal objeto (Abascal, 2004: 9).
}

mas prototípicas de la oralidad), y junto a estas formas, existen variaciones debidas a cambios, más o menos drásticos, operados en alguno (o en varios) de esos parámetros, siendo las más relevantes las introducidas por la tecnología, pero no necesariamente las únicas (2004: 21).

Nuevamente se resalta aquí el papel de la oralidad en las TICs, tema que abordaré más adelante. Por ahora, me interesa acercarme a la elucidación de categorías analíticas que posibiliten pensar la oralidad en la dinámica escolar, situarla en la práctica pedagógica no como un hecho de realización individual alejado del contexto y de la transacción, sino como un saber que permite a los actores pedagógicos analizar los discursos que circulan en el aula y vislumbrar el camino hacia el estudio sistemático del discurso no sólo a nivel descriptivo y analítico, sino también social y político (van Dijk, 2001b).

\section{Categorías analíticas}

Son múltiples los caminos que se pueden seguir para realizar un análisis del discurso en el plano de lo oral. A continuación presentaré algunas categorías básicas en el intento por acercarme a la naturaleza interactiva y práctica del discurso, no sin antes reconocer que estas reflexiones están circunscritas a postulados epistemológicos y metodológicos propuestos por

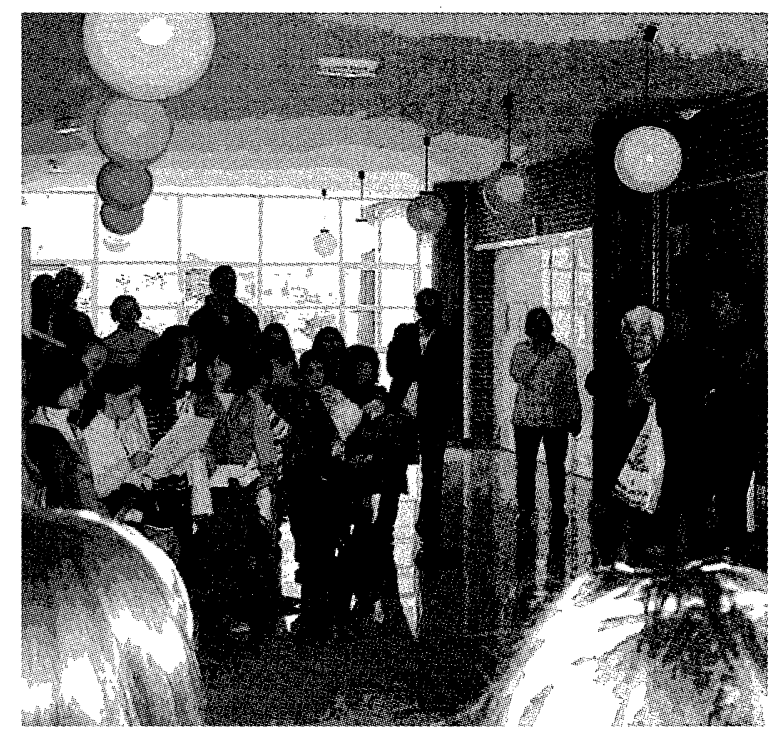


teóricos y analistas del discurso como van Dijk (2001a), Fairclough (2003), Wodak (2003), van Leeuwen (1996), Vasilachis (1997), Soler (2007) y Pardo (2007), entre otros, quienes presentan el análisis del discurso como un campo disciplinar reciente que surge del estudio de un conjunto de manifestaciones verbales articuladas a procesos de conocimiento y formas de construcción y reproducción. Además, coinciden en el análisis crítico del discurso (ACD) como un enfoque que se interesa por los modos en que se utilizan las formas lingüísticas en diversas expresiones y manipulaciones del poder.

Desde esta perspectiva lingüística y social, el análisis del texto y el contexto resulta crucial para el ACD, por ello abordaré la descripción del contexto local y global propuesto por van Dijk (2003) seleccionando algunos elementos analíticos.

\section{El contexto}

La noción de contexto es fundamental en el análisis del discurso oral y en general en los estudios discursivos-textuales y su tratamiento no se restringe a la visión cotidiana del lugar o de la circunstancia: de ser así se reduciría a una dimensión gramatical y no discursiva como pretendo. Si se analiza el discurso desde la perspectiva social, se reconoce el dinamismo de los sujetos que participan en la interacción verbal, el tiempo y el lugar de la situación de producción del discurso.

En este sentido, van Dijk define el contexto como "la estructura de aquellas propiedades de la situación social que son sistemáticamente (es decir, no causalmente) relevantes para el discurso" (2001a: 33). Es el caso de los participantes, el marco, la utilería, las acciones y los conocimientos e intenciones. Propone el análisis del contexto global o social, mediante el cual se estudian las estructuras sociales, políticas, culturales e históricas en las que tienen lugar los acontecimientos comunicativos, y del contexto local o interactivo, que se ocupa de situaciones inmediatas e interactivas, por ejemplo: qué se dice, cómo se dice, quién lo dice y a quién, cuándo y dónde lo dice y cuál es su propósito. Lo anterior implica la tarea de caracterizar a los participantes, identificar la relación que establecen con otros o con nosotros y demás factores presentes en el momento de la emisión.

También plantea la existencia de un control sobre estos contextos (local y global) en tanto los sujetos sociales más poderosos pueden dominar el discurso seleccionando el lugar, los participantes, las audiencias, los actos de habla, el tiempo, los temas, el género y los estilos. Por ello, es importante tener en cuenta, entre otros aspectos:

- La selección de turnos y distribución de papeles. Podemos observar qué influencia tienen las personas o grupos dominantes con respecto al que habla sobre un determinado tema, a quién puede dirigirse, de qué manera y en qué circunstancias. Aquí toma gran importancia el papel discursivo del hablante y las categorías fijas tradicionales que se han definido socialmente: quién comienza el discurso, quién lo puede continuar, quién lo puede cerrar.

- El acceso diferencial a los actos de habla. La persona que posee el poder determina el género que se utilizará en una situación de habla y su duración. Esto muestra que el acceso a los géneros es diferente y que algunos no tienen realmente acceso libre a los discursos. Quien controla el género discursivo ejerce también un control sobre los actos de habla.

\section{El texto}

En un análisis discursivo es inherente el texto en tanto discurso que producen los hablantes en una situación particular. Los hablantes construyen modelos mentales de la situación de intercambio verbal en la que participan. Por ello, se puede indagar por quien inicia o termina la conversación, o quizás por el que cambia de tema y el que lo retoma. En todo caso, se ejerce un control sobre los aspectos del discurso y de la comunicación. Van Dijk (2003) sugiere que para detectar las formas de control sobre el texto, ya sea oral o escrito, se puede partir de las propiedades o categorías que los discursos poseen y que dan paso a las elites para legitimar o convocar y tener control sobre los oyentes/lectores. El aná- 
lisis de algunas estructuras de superficie contribuye a esta tarea:

- El nivel léxico es el más controlado dèntro del esquema lingüístico. Es importante observar la selección de las palabras. Esto significa que la manera de definir a la gente depende mucho de la posición de quien habla o escribe. La selección del léxico en la presentación de otras personas a todo un grupo es una manera de ejercer control sobre la mente del auditorio. Van Leeuwen (1996) propone el diseño de un inventario sociosemántico para analizar la representación de los actores sociales en el discurso. Teniendo en cuenta esta estrategia, se considera que mediante una selección intencionada de palabras podemos asignar un sentido o construir una imagen.

- El control de la entonación. En la comunicación oral existe un control de la entonación que define quién tiene o no legitimidad y autoridad para alzar la voz. A este respecto hay muchísimos aspectos que expresan de manera directa la noción de poder, por ejemplo, se puede ejercer abuso de poder gritando; sin embargo, este aspecto del discurso oral es complejo de analizar.

- El control de las estructuras de tema. Las preguntas básicas que guían la investigación son: ¿de qué habla la gente?, ¿de qué se puede hablar y quién impone las limitaciones? En este aspecto hay un control bastante fuerte, es decir, en la mayoría de las situaciones tenemos limitaciones en la libertad de escoger los temas.

\section{Presupuestos metodológicos}

La investigación es de carácter exploratorio, descriptivo y proyectivo, y no parte de los paradigmas que abordan la escuela y los actores educativos como meros objetos de investigación para producir teorías que expliquen la problemática desligada de la praxis, sino desde la problematización de su misma realidad, donde las interacciones y la experiencia colectiva se constituyen en objetos de estudio y los sujetos implicados asumen el rol de participantes activos y transformadores de su propia realidad.
Me refiero a la investigación cualitativa que ofrece un amplio espectro de posibilidades de acción y teorización. Su enfoque metodológico y su fundamentación epistemológica son de orden descriptivo, explicativo e interpretativo, características que permiten diseñar una red cuyo entramado está conformado por la visión del investigador y las teorías que sustentan la intervención del contexto particular y el grupo social afectado.

La recolección de datos se realizó mediante tres instrumentos principales: el diario de campo, las audiograbaciones y la aplicación periódica de entrevistas semiestructuradas. Para el análisis y sistematización de datos construimos categorías basándonos en la información recogida antes, durante y después del proyecto de aula.

\section{Esta experiencia nos ha planteado cambios en el contrato didáctico en términos de asumir la responsabilidad del aprendizaje de manera equitativa (maestros y estudiantes), sin desconocer el andamiaje teórico-práctico que proporcionan los maestros a los estudiantes.}

Cabe anotar que la perspectiva metodológica de esta investigación es objeto de enseñanza y aprendizaje para la población estudiada, es decir, el objetivo central del proyecto pedagógico es formar estudiantes investigadores con pensamiento epistémico, que logren pasar del conocimiento práctico a un conocimiento reflexivo y elaborado, en el sentido en que lo plantea $\mathrm{Ma}$ rio Testa: " $\mathrm{El}$ sujeto epistémico abandona la ambigüedad originaria del lenguaje cotidiano, y se ciñe a acepciones precisas a fin de construir su objeto de investigación" (1996: 25).

Formar estudiantes investigadores en educación media implica llamar la atención sobre la necesidad de articular políticas de formación en investigación, es decir, decisiones y planteamientos deliberados y coherentes que principalmente articulen objetivos, proyecten acciones en relación con la educación superior, unan esfuerzos, combinen recursos, definan metas y planteen resultados esperados, bajo condiciones de control y verificación. En palabras de Splitter y Sharp: 
Considérese, entonces, el llamado de los tiempos modernos a incluir la "investigación" dentro de los elementos básicos de la educación, como mínimo para los estudiantès de nivel medio. Este llamado dará sus frutos si y sólo si los estudiantes comprenden y aplican el principio según el cual el nivel superior, pensamiento orientado a la investigación, esencialmente basado en un problema y auto correctivo, es vastamente dialógico en estructura [...] se infiere de esto que la mejor forma de preparación para comprometerse en tal indagación es la participación temprana y continua en una comunidad de indagación dialógica (1996: 66).

De otra parte, es necesario reflexionar sobre la distinción entre enseñar a investigar y hacer investigación. Todos (maestros y estudiantes), hemos transitado los caminos de la investigación, sin embargo, no es lo mismo la investigación cotidiana de preguntarnos e indagar por situaciones, palabras, hechos, etc., ejercicio que normalmente culmina con un informe o un trabajo para demostrar los aprendizajes logrados sobre un tema particular, que hacer investigación formal para darle explicación o solución a un problema que hemos identificado y sobre el cual nos hemos propuesto realizar un seguimiento, confrontar y sistematizar. Es decir, asumir la investigación desde la clásica idea de enseñar a partir de la práctica (a investigar se aprende investigando) en términos procesales y sistemáticos, que trasciendan la teoría, confronten la realidad y conduzcan a la construcción de nuevos conocimientos, de conclusiones susceptibles de ser verificadas y al logro de un acercamiento a la certeza.

En esta perspectiva se sitúan nuestros primeros esfuerzos, en vincular a los mismos estudiantes en experiencias estructuradas y sistemáticas y orientarlos hacia la adopción de una actitud investigativa; de ahí la necesidad de involucrarlos en búsquedas, cuestionamientos, interacciones y propuestas de acción en relación con su realidad social, cultural, histórica, política y científica. Esta tarea implica también coadyuvar a que el estudiante sea capaz de desaprender o romper con un sistema de creencias y certezas y logre acercarse a la realidad, tomar datos, convertirlos en aprehensibles e inteligibles de manera que la lectura, la es- critura y el discurso oral se constituyan en mediaciones fundamentales de la investigación y específicamente del objeto de estudio.

Esta experiencia nos ha planteado cambios en el contrato didáctico en términos de asumir la responsabilidad del aprendizaje de manera equitativa (maestros y estudiantes), sin desconocer el andamiaje teórico-práctico que proporcionan los maestros a los estudiantes. Además, nos ha exigido fijar una mirada más profunda en los acontecimientos y situaciones que viven los estudiantes de hoy con respecto a sus modos de acceder a nuevas formas de interacción y construcción de saberes. Por tal razón, nos hemos acercado al uso de las TICs, uno de sus verdaderos intereses, quizás el más evidente en cuanto a que es la red virtual la que satisface ampliamente sus necesidades académicas $\mathrm{y}$, sobre todo, sociales.

\section{Contexto de aplicación de la propuesta didáctica}

Esta experiencia se inscribe en el proyecto pedagógico "Formar estudiantes investigadores en educación media: utopía o reto", el cual surge, en primer lugar, por la necesidad de fortalecer la producción oral y escrita de los estudiantes de educación media de la Escuela Normal Superior Distrital María Montessori y, en segundo lugar, por el interés de ellos en divulgar sus producciones escritas a través de un medio virtual, espacio que consideran atractivo y eficaz para dar a conocer a una amplia variedad de lectores sus ideas, informaciones, acciones y juicios de valor en torno a temáticas de orden social, cultural, político y educativo. Los aportes de los estudiantes de $11^{\circ}$ a las dos últimas ediciones de la revista digital estudiantil ${ }^{5}$ emergieron del proyecto de aula denominado "Explora, conoce y vive tu Bogotá", estrategia didáctica que contó con el apo-

\footnotetext{
5 La revista digital ACCES (Actitud Estudiantil) se encuentra alojada en la página web del colegio (http://colegios.redp.edu.co/ensdmm). Durante el año escolar los estudiantes de media $\left(10^{\circ}\right.$ o $\left.11^{\circ}\right)$ convocan a todos los compañeros de la institución (preescolar hasta ciclo profesional) a publicar diversos textos, videos, fotos, música y demás producciones ideadas por ellos o con el apoyo de sus profesores.
} 
yo permanente de la profesora de Informática y Tecnología, quien asesoró el acercamiento de los estudiantes a las Tics y de un equipo de estudiantes en formación inicial, ${ }^{6}$ quienes coadyuvaron en el proceso investigativo. Éste se desarrolló en cuatro etapas:

\section{Exploración e indagación en fuentes virtuales}

Esta etapa representó el mayor reto en relación con el hecho de asumir el rol de estudiantes investigadores. Inició con el diálogo en relación con sus inquietudes e iniciativas para transformar problemáticas propias de su entorno: en este escenario dialógico los jóvenes comprenden que hay nuevas y diferentes formas de pensar un.problema y definir una ruta a seguir, de ahí las primeras exploraciones en bibliotecas virtuales, enciclopedias en línea, bases de datos, imágenes, música y videos digitales ${ }^{7}$. Este acercamiento actúa como "gatillador" que seduce a los estudiantes en la conformación de grupos de investigación interesados en indagar sobre tópicos comunes utilizando el abanico de posibilidades de la tecnología multimedial, hecho que los convoca en la cons-

6 Futuros maestros, pertenecientes a la Licenciatura en Lengua Castellana y Humanidades de la Universidad Distrital. Cabe anotar que este tipo de convenios fortalece la relación escuela-universidad y posibilita el diálogo en relación con el desarrollo de prácticas pedagógicas de carácter investigativo.

7 Por ejemplo: http://www.colombiaaprende.edu.co/ html/home/1592/channel.html, biblioteca virtual. http://www.mineducacion.gov.co/cvn/1665/channel. html, centro virtual de noticias.

http://www.biblored.org/, red capital de bibliotecas públicas.

http://www.redacademica.edu.co/redacad/export/REDACADEMICA/estudiantes/, centro de documentación. www.ipl.org, biblioteca pública de Internet. www.http://www.quadernsdigitals.net/, hemeroteca y biblioteca virtual.

http://www.eltiempo.com/, http://www.elespectador. com/, prensa digital.

http://www.bogotaturismo.gov.co/camp_publicidad/ nuevabog.htm, web de fotos y videos sobre Bogotá. www.toptutors.com, tutoría en línea; http://www.educaweb.com/, portal educativo.

Fuente académica base de datos multidisciplinaria, http:// www.ebscohost.com/.

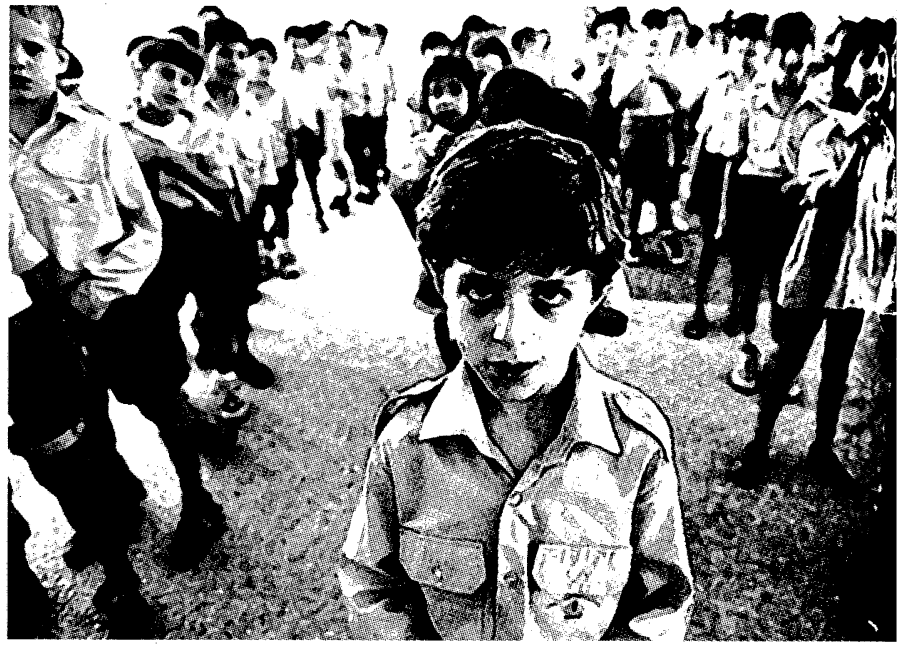

trucción de un proyecto colectivo, estructurado y sistemático. De esto da cuenta la voz de un estudiante tomada de la socialización del proyecto ante la comunidad montessoriana:

Diseñamos el anteproyecto o propuesta de investigación, fue una tarea difícil porque nos exigió planear, discutir y tomar decisiones; simultáneamente indagamos en diferentes fuentes de Internet. Esto fue crucial porque tuvimos que leer muchos textos y de diferente tipo, los cuales fuimos entendiendo mediante el uso de estrategias lectoras, esto fue clave para tener claridad sobre la problemática bogotana que escogimos. Esta etapa se evidencia en estos portafolios, aquí podemos ver documentos sobre indagaciones relacionadas con [...] (2007, diciembre, grabación en audio).

Cabe anotar que en esta etapa se llevó a cabo una actividad con otra herramienta de Internet, el blog, cuyo corpus es objeto de análisis en este trabajo.

\section{Recolección, contraste y análisis de datos}

Etapa que definimos como "trabajo de campo", la cual tiene distintos matices de acuerdo con el enfoque investigativo en el que nos situemos. En este caso el contexto de indagación es Bogotá D.C., por lo tanto, los estudiantes acuden a la ciudad en busca de personas, instituciones y luga- 
res que le aporten nuevos datos a la problemática que abordan. Para ello, cuentan con instrumentos etnográficos como la encuesta y. la entrevista y con artefactos tecnológicos como la cámara, el celular o la videograbadora. Veamos la manera como lo explica un estudiante en una entrevista realizada en el marco de un foro local ${ }^{8}$ sobre experiencias pedagógicás innovadoras:

Entrevistador: ¿Qué fue lo que más-le llamo la atención del proyecto?

Estudiante: Para mí, fue muy importante el trabajo de campo porque tuvimos que contactar a personas, instituciones y recorrer lugares de la ciudad para conseguir nuevas informaciones, y luego al analizar las entrevistas y encuestas y compararlas con la información obtenida en la primera etapa fue muy. bacano porque ahí uno se da cuenta qué tan confiable es la información de los libros, revistas y periódicos que consultamos: Otra cosa interesante fue construir estas galerías de fotos que muestran el resultado de nuestro trabajo.

Es importante destacar cómo, a nivel discursivo, esta etapa permite poner en escena la competencia de los participantes para dialogar con otros y a nivel intelectual les permite encontrar contradicciones, corroborar situaciones y lograr posibles hallazgos.

\section{Producción escrita y socialización de resultados}

La etapa de producción es la más compleja del proceso, ya que se trata de escribir el resultado de la investigación mediante uno de los tres géneros discursivos propuestos: argumentativo, expositivo e informativo' ${ }^{9}$, de tal forma que involucre elementos de las dos etapas anteriores. Así lo registra en su diario de campo uno de los maestros practicantes:

8 Foro Feria Pedagógica Local realizada en el colegio Atanasio Girardot en agosto de 2007.

9 Cabe aclarar que en cada experiencia seleccionamos unos géneros discursivos, teniendo en cuenta la diversidad de textos que se publican en las secciones de la revista digital.
En esta clase procedemos con la profesora a revisar el segundo borrador del texto que está escribiendo cada estudiante, la estrategia utilizada es comparar el plan de escritura con el contenido del texto que presenta [...] coMENTARIos: Una de las estrategias que mantuvo atentos e interesados a los estudiantes fue la revisión de los borradores mediante el correo electrónico. Esta correspondencia electrónica agilizó el proceso de reescritura, posibilitó no imprimir borradores, no gastar papel, no hacer uso de útiles escolares como el borrador, las tijeras, el pegante, porque existe esta misma representación en el ordenador (Barrera, 2007).

Todos sabemos que investigar implica leer y escribir, sin embargo, este último proceso genera angustias y muchas veces el estancamiento de un proceso que ha sido enriquecedor. Aunque en todo momento se intenta dar ánimo al estudiante, muchos no llegan a culminar esta etapa. La socialización de los resultados de la investigación se realiza a través de la revista virtual y de eventos a nivel institucional y distrital. En el esquema 1 se ilustra el diseño didáctico de estas etapas y acciones intrínsecas que validamos año tras año con nuevos temas o "pretextos" que hacen posible acercarnos a la formación de estudiantes investigadores.

\section{Análisis del discurso de los estudiantes en el blog ${ }^{10}$}

En la primera etapa de la experiencia pedagógica descrita se llevó a cabo una actividad correspondiente a la visita virtual al portal turís-

${ }^{10} \mathrm{E} 1$ término blog, o en español bitácora, proviene de las palabras web y $\log$ ( $\log$ en inglés = diario). El término bitácora, en referencia a los antiguos cuadernos de bitácora de los barcos, se utiliza preferentemente cuando el autor escribe sobre su vida propia como si fuese un diario, pero publicado en Internet. Los blogs ofrecen un espacio para escribir, constituido en dos terceras partes por un diario en línea y en una tercera parte por una herramienta de discusión. Los blogs proveen un foro que invita a realizar comentarios y a discutir. http://es.wikipedia.org/ wiki/Blog. 
tico de Bogotá. ${ }^{11}$ La consigna consistía en navegar por el portal, conocer sus servicios (entre los que suelen encontrarse buscadores, foros, documentos, compras electrónicas, etc.) y, luego, leer en pantalla el texto correspondiente a la campaña "Y tú, ¿qué sabes de Bogotá?", orientado a invitar a propios y extraños a descubrir una ciudad diversa. La manera como se abordó la interpretación de este texto fue mediante el blog digital. Los blogueros accedieron a él para expresar allí sus comentarios, inquietudes y propuestas sobre lo que conocen acerca de su ciudad.

El modus operandi de los blogs tiene que ver con la recopilación cronológica de los comentarios de sus usuarios con respecto a un tema de interés común, un artículo o una noticia de actualidad. De esta manera, se establece un diálogo entre blogueros o foristas, quienes conforman una comunidad de lectores y comentaristas. En consecuencia, el propósito de esta actividad se orienta a realizar un análisis lingüístico-discursivo de los comentarios aportados por los estudiantes. Este análisis se efectuó en el aula de clase con los mismos estudiantes a partir de las categorías de contexto y texto, sustentadas aquí anteriormente, porque intentamos acercarnos a los rasgos orales no para remarcar sus usos espontáneos o para hacer juicios en términos de lo correcto o incorrecto, sino para ver de qué manera nos servimos de expresiones cotidianas para lograr nuestros propósitos comunicativos y la.actitud que asume el comentarista cuando se expresa por medio de este tipo de textos. Porque no es posible dar cuenta de todos los comentarios e interpretaciones, en el esquema 2 sólo presentamos algunas estructuras relevantes para intentar establecer vínculos entre el texto y el contexto.

La primera reflexión se orientó a identificar el contexto social y discursivo a partir de las preguntas: ¿qué se dice?, ¿cómo se dice? Acudimos a construir el inventario léxico, con el fin de identificar los sustantivos, los deícticos (de persona y. lugar) y los enunciados usados para categorizar, calificar y definir a los actores y al contexto de esta situación comunicativa.

\footnotetext{
${ }^{11} \mathrm{http} / /$ www.bogotaturismo.gov.co/, portal oficial del tu-
} rismo en Bogotá, Instituto Distrital de Turismo.
Analizar de qué se habla y cuáles son las expresiones utilizadas para ello nos sitúa en un espacio limitado en tanto el tema central está predeterminado por la pregunta en relación con lo que conocen de Bogotá; sin embargo, surgen otras categorías que contribuyen a configurar el contexto social y discursivo. La discriminación: ${ }^{12}$ "Eso se llama discriminación y no sólo del gobierno, también de los bogotanos"; el desempleo: "la falta de empleo"; el sistema de transporte: "lo último que han hecho el transmilenio"; la recreación: "De lo que conozco solo puedo hablar de Monserrate, el parque Simón Bolívar y algunos museos Ah! y las megabibliotecas publicas"; la educación: "muchos nos quedamos sin estudio por falta de platica"; la inseguridad: "todos esos desocupados que roban y matan sin compasión”; el conflicto armado: "hasta los guerrillos que ya se nos metieron a la ciudad". La referencia más específica al contexto se evidencia en la actividad lingüística de los interlocutores, los cuales hacen uso de los deícticos de lugar: "allá en el norte", "Aquí muchos se preocupan más por tener una buena imagen", "acá tenemos atractivos lugares". Es un uso deíctico de carácter simbólico que cumple la función de identificar el lugar en el que se desarrolla el evento comunicativo (Calsamiglia y Tusón, 2002: 119).

De lo anterior se deduce que estos jóvenes foristas se refieren al contexto desde dos perspectivas: el "contexto catástrofe", en tanto se realiza una descripción apocalíptica de la situación, y el "contexto de la modernidad", asociado a una descripción de una situación en proceso de modernización o transformación (Vasilachis, 1997). Además, se valen de variados recursos lingüísticos para referirse al tema del que se habla; en este aspecto se hace evidente el control del tema (van Dijk, 2003) a partir de la persona que lo propone (profesor), el que inicia la interlocución, " $\mathrm{Ex}-$ celente esa pregunta", y el que al final retoma y ubica a los demás: "Estoy de acuerdo con todos ustedes, pero a este foro venimos a hablar de qué conocemos de Bogotá".

\footnotetext{
${ }^{12}$ La negrita la utilizo para remarcar las palabras o expre-
} siones clave. 


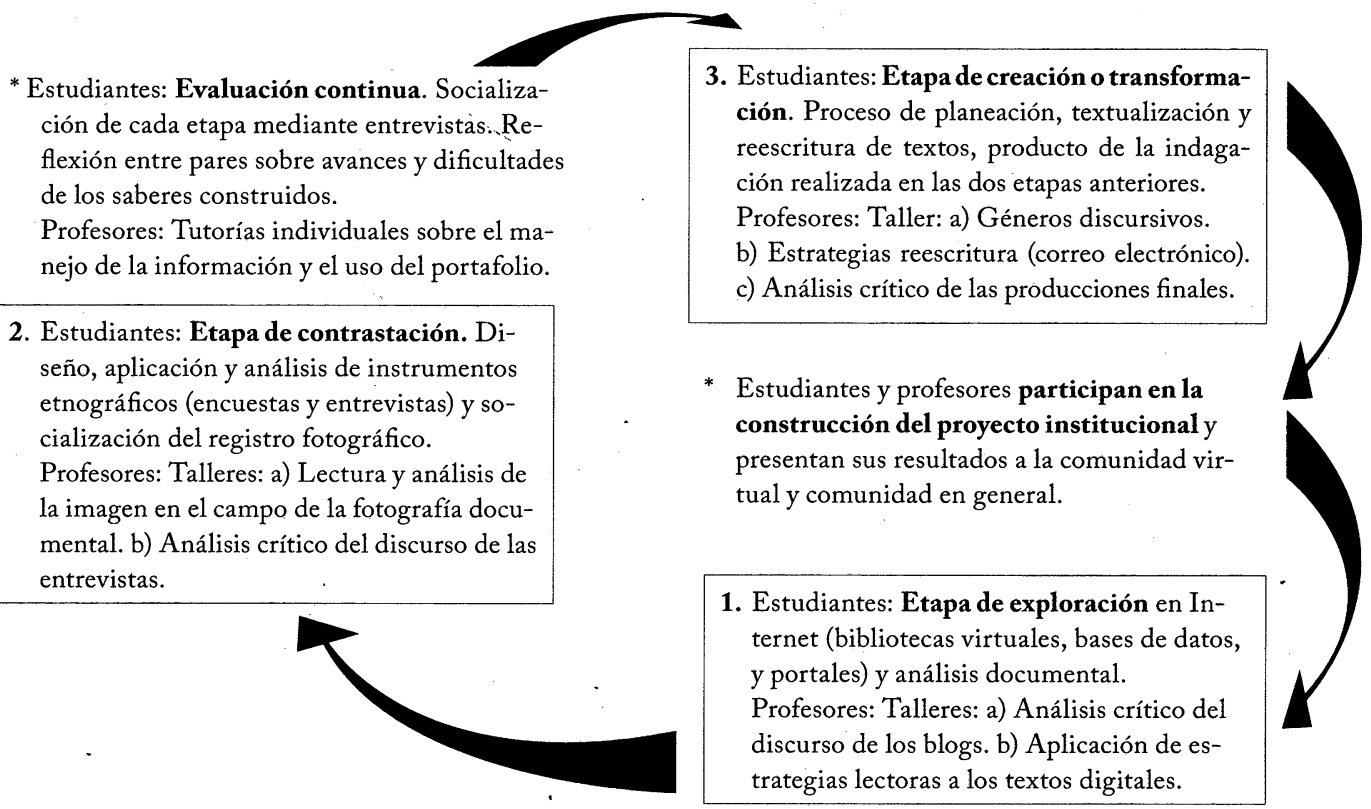

Esquema 1: Aprender a investigar para transformar y/o transformarnos.

Propuesta didáctica de investigación ẹn la escuela.

Severo: Excelente esa pregunta, pero quien tenía la obligación de responderla ha debido ser el alcalde lucho garzón. Porque é no conoce todos los problemas que se viven en Bogotá el transporte, la falta de empleo y sobre todo las necesidades que tenemos nosotros los jóvenes, por ejemplo este año salimos y muchos nos quedamos sin estudio por falta de platica.

Travel: La verdan no se mucho de Bogotá, tal vez lo último que han hecho el transmilenio, las blibliotecas y nuevos parques. De lo que conozco solo puedo hablar de Monserrate, el parque Simón Bolívar y algunos museos Ah! y las megabibliotecas púyblicas que conozco por los paseos del colegio. Estoy de acuerdo con el compañero hay muchos problemas y los alcaldes y el gobierno solo se fijan en lo que pasa allá en el norte para el sur poco miran.

Lulú: Eso se llama discriminación y no sólo del gobierno, también de los bogotanos, los bogotanos, son secos frios, egoistas y excluyentes. Eso lo compruebo todos los días. En realidad la gente que le da calor armonía, amistad y hacen la vida agradable en nuestra bella ciudad es la que viene de afuera y se queda, los paisas, los pastusos, los boyacos, los costeños y nosotros los caleños.

Racho: O sea que nosotros mismos nos excluimos, me parece ridículo como discriminan a la gente en los bares de la zona rosa o de la 93. Prefieren que entre alguien que se acomode a la imagen prediseñada que tienen en sus mentes. Lo más gracioso es que siempre el "filtro" un tipo que no tiene educación ni sentido estético como para poder juzgar a nadie es el que decide quien entra y quien no. Es tan ridículo que una vez escuche decirle a alguien que no podía entrar porque el gel ya pasó de moda... jajaja

Ponky: Oigan!!!!!!! no todo es malo, nombraron a Bogotá capital mundial del lịbro y eso hará que muchos extranjeros la visiten e inviertan en ella, ¿no les parece genial?

Chucho: Si seguramente, eso es bueno, pero seamos realistas, la mayoría de la población lee cada vez menos, y no hablo solo de nosotros sino de los más chicos, Aquí muchos se preocupan más por tener una buena imagen, usar los mejores zapatos, corte de moda, la mejor pinta o lo que está más de moda y los medios de comunicación se interesan por mostrar más farándula, más fútbol, más superficie. Ahh, pero la imagen de Bogotá en el exterior no es muy célebre, a bogotá la habitan las "ratas", todos esos desocupados que roban y matan sin compasión, los corruptos políticos y hasta los guerrillos que ya se nos metieron a la ciudad esos desalmados criminales farcsantes "20\% 22*\}\{\#\#\#"'" \&\&\% “ ¿Qué imagen tan bonita no? Saliva: Estoy de acuerdo con todos ustedes, pero a este foro venimos a hablar de qué conocemos de Bogotá, ya vimos en el portal del instituto de turismo el cambio que ha tenido nuestra ciudad, acá tenemos atractivos lugares, buenas cosas y muchas costumbres que hay en mi ciudad de origen. No la denigremos más sino empecemos a pensar como contribuimos para mejorarla para conocerla más, hay muchos lugares para el ocio y la diversión, también para aprender y crecer, entonces lo que tenemos que hacer nosotros es querer nuestra ciudad, ayudarla a mejorar y sentirnos orgullosos de ella.

Esquema 2: Corpus tomado del blog digital. 
La segunda reflexión explora el texto a partir de la actividad lingüística de los miembros: ¿quién lo dice y a quién? y ¿cómo lo dice y cuál es su propósito? Los foristas, estudiantes de educación media, se representan como actores pertenecientes a una colectividad, emplean el "nosotros" para involucrar a los otros e institucionalizarlos, ${ }^{13}$ "las necesidades que tenemos nosotros los jóvenes", "hacen la vida agradable en nuestra bella ciudad", "lo que tenemos que hacer nosotros es querer nuestra ciudad, ayudarla a mejorar y sentirnos orgullosos de ella". Calsamiglia y Tusón lo denominan como el uso de un "nosotros inclusivo", "aquel que incorpora al receptor en la referencia al emisor. Puede ser un uso intencionado para acercar las posiciones de los protagonistas de la enunciación, y se da en todos los casos en que es importante para el emisor la involucración del receptor" (2002: 140).

También se da una colectivización de otro orden, cuando hacen referencia a los que discriminan: racistas; a las autoridades de la ciudad: gobierno; a los que informan: medios de comunicación; a los que comenten actos ilícitos: delincuentes; a algunos actores del conflicto armado: guerrilleros; a los más chicos: niños, y a los ciudadanos en general.

Se emiten diversos juicios a partir del $\mathrm{ca}^{-}$ rácter de institucionalidad dado a los sujetos "é no conoce todos los problemas que se viven en Bogotá", "hay muchos problemas y los alcaldes y el gobierno solo se fijan en lo que pasa allá en el norte para el sur poco miran", "la gente que le da calor armonía, amistad y hacen la vida agradable en nuestra bella ciudad es la que viene de afuera y se queda", "el "filtro" un tipo que no tiene educación ni sentido estético", "los medios de comunicación se interesan por mostrar más farándula, más fútbol, más superficie", "la habitan las "ratas", todos esos desocupados", "los corruptos políticos", "esos desalmados criminales farcsantes".

Como puede verse, el enunciador se representa como legitimado para prescribir las acciones y comportamientos de otros actores sociales: predica y atribuye acciones que se constituyen en valoraciones positivas o negativas. Son evaluacio-

\footnotetext{
${ }^{13}$ Van Leeuwen (1996) habla de generización donde las clases o las esencias generalizadas corresponden a lo real.
}

nes consistentemente negativas cuando define las acciones realizadas por otros, en contraste con las acciones realizadas por aquellos cercanos al enunciador o al "nosotros", estableciendo una división binaria entre grupos, donde se asocia el valor bueno con nosotros y lo malo y desagradable con ellos.

En algunos comentarios subyace una violencia simbólica, cuando se presentan las zonas habitadas por los sectores excluidos o los responsables de los problemas que agobian a la ciudad, con lo cual se intensifica el peso de la dominación simbólica que los habitantes de estos lugares deben sufrir. Los problemas de orden social y económico se asocian con la exclusión activando nociones de sentido común que legitiman el prejuicio, ya que se marca la existencia de un mundo compartido entre dos clases de individuos: aquellos que responden al modelo valorado socialmente y los que pertenecen a los "márgenes", "la periferia", donde se desarrolla la "subcultura de la pobreza".

La relación texto-contexto emerge de la relación actores-acciones, la cual se caracteriza mediante nominalizaciones, sustantivos de proceso y deícticos que constituyen una carga léxica que a su vez configura una red semántica (Vasilachis, 1997). El nudo de esta red semántica o el punto donde convergen todos los enunciadores, independientemente de su rol o de su posición social, política, económica y cultural, es la percepción de la ciudad, el lugar que todos habitan.

Por último, es importante tener en cuenta que estas categorías se aplican indistintamente a discursos escritos u orales; no obstante, estos últimos tienen algunas características particulares. Por ejemplo: en las conversaciones públicas por lo general existe un ritual de saludos y presentaciones; no ocurre lo mismo en este foro virtual: parece ser suficiente el seudónimo del interlocutor para responder a un comentario o simplemente expresar el propio. Esto podría hacernos pensar en que la tradición normativa del comportamiento en la vida social puede estar en proceso de decadencia en lo que respecta a la red virtual, posiblemente debido a la velocidad con que se opera en ella. Sin embargo, la cortesía ${ }^{14}$

\footnotetext{
${ }^{14}$ La cortesía fue abordada por Searle (1969), quien fue el primero en hablar de las reglas reguladoras en la con-
} 
no se refiere sólo a la norma social, también a aspectos como el uso de ciertos indicadores lingüísticos. En este caso se reconoce la función interactiva del blog a través de expresiones como "O sea que", "Estoy de acuerdo!", "Si seguramente", que denotan consenso y armonización de las relaciones sociales y discursivas.

El lenguaje de los blogs y de otros medios virtuales intenta representar la entonación, el volumen, los gestos y los movimientos y posturas del cuerpo propios de la oralidad, para ello los interlocutores se valen de recursos icónicos como los emoticonos, ${ }^{15}$ que ayudan a expresar este tipo de situaciones inusuales en el discurso escrito, pero recurrentes en las conversaciones orales. En este corpus notamos el uso de expresiones como “... jajaja”, "Oigan!!!!!!!” o “farcsantes “20\% 22*\} \{\#\#\#\%\%\&\% “”, que intentan representar expresiones y acciones propias del discurso oral.

\section{Conclusiones}

A pesar de que el objetivo de este trabajo se concentra en analizar cómo inciden las TICs en el fortalecimiento del discurso oral, es inevitable la emergencia de otros propósitos, ya que el discurso oral adquiere dimensiones insoslayables cuando se aborda en conjunción con el discurso electrónico, en cuanto implica la construcción de nuevas formas de significación. Analizar la pluralidad de voces convocadas o silenciadas en el discurso electrónico concita nuevos propósitos en la enseñanza universal y democrática.

$\mathrm{El}$ análisis del discurso oral con frecuencia se ignora en la escuela; no se trata de adicionar otra tarea a las ya previstas en la enseñanza, sino de diseñar estrategias didácticas que permitan equiparar el tratamiento del discurso oral y escrito, por ejemplo: en este caso analizamos la relación texto-contexto en un discurso tomado del aula para comprender la riqueza de su dimensión

versación; luego Grice (1975) propuso las máximas conversacionales.

${ }^{15}$ Cassany (2006) explica el uso de los emoticonos como recursos que suplen estados emotivos: reír, llorar, besar, abrazarse, mostrar tristeza o alegría, acciones cruciales en la interacción verbal cara a cara. social y discursiva. También podemos abordar el análisis de aspectos específicos del discurso oral como los elementos no verbales o los prosódicos, entre otros.

Construir conciencia en relación con el tratamiento dado a nuestro discurso en el aula contribuye a despojarnos de los prejuicios de lo correcto e incorrecto, de la idea de que el profesor es el que habla y de que cuando interactúa verbalmente con los estudiantes lo hace a través de la pregunta. Significa también atreverse a proponer un nuevo discurso o "contrato didáctico" donde el aula sea un escenario discurșivo y el uso consciente de la lengua oral posibilite organizar el pensamiento, dinamizar las interacciones, los intercambios y la participación equitativa. Abascal plantea la necesidad de

establecer una secuenciación adecuada para que el intercambio comunicativo que se desarrolla en el aula vaya evolucionando, de acuerdo con las necesidades que se derivan de la ampliación del conocimiento y como consecuencia del desarrollo de las destrezas comunicativas. Llevar a cabo esta secuenciación significará intervenir didácticamente en un terreno que hasta ahora parece dominado por la intuición y la improvisación (1993: 116).

Fundamentar la enseñanza y el aprendizaje de un campo disciplinar en la actividad de la investigación nos estimula a vincular a los estudiantes en proyectos institucionales y orientarlos hacia la adopción de una actitud investigativa desde una "práctica teorizante". En nuestro caso, vivimos la experiencia de conformar semilleros de investigación con estudiantes interesados en indagar sobre la realidad social, cultural, histórica, política y científica de Bogotá de manera estructurada y sistemática, experiencia que les posibilitó involucrarse en búsquedas, cuestionamientos, interacciones y propuestas de acción.

De otra parte, las bondades que encontramos en el uso del blog, además de ser un medio de comunicación escrito "oralizado" que nos permite ver como los usuarios utilizan el código escrito para acercarse al oral, son: lograr implicar en la discusión a todos los participantes, quienes superan el nerviosismo que algunos padecen ante 
el hecho de expresar sus puntos de vista en público; familiarizarnos con nuevas estructuras discursivas reflejadas en hipertextos, hipervínculos, frases de cortesía diferentes a las tradicionales y registros lingüísticos como minimizar, adjuntar, antiespia,spam,niñ@s, guguelear, chatear, colgaren la red, entre otras (Cassany, 2006), y la manera como introducimos una serie de esquemas simbólicos para representar las acciones que realizamos oralmente como gritar: auxilioooo!!, reír: jajaja, vociferar: “20\% 22*\}\{\#\#\#\%\%\&\%”, 1lamar la atención: uffffffffffffffff. De esta manera, las nuevas generaciones han conformado nuevas comunidades discursivas planteándonos el reto de asumir la literacidad electrónica como una nueva dimensión discursiva con diversas prácticas comunicativas. He aquí la tarea de los analistas críticos del discurso en relación con un nuevo género discursivo, el género electrónico.

La indagación en Internet requiere del conocimiento por parte del cibernauta de sus-derechos, deberes y habilidades para la búsqueda. Uno de ellos es la facilidad de acceso a diferentes documentos, sin embargo, es importante enseñar a identificar su estructura, sus enlaces, su validez y utilidad. Además, concienciar sobre el tratamiento de la información, es decir, su uso ético y crítico $y$, en consecuencia, experimentar otros modos de hablar, leer y escribir, situación que nos convoca a repensar la formación de las nuevas generaciones.

El uso de las Tics como herramientas educativas atrae a los estudiantes y los motiva a aprender. García y Quintana (2004) reflexionan sobre los beneficios tanto para docentes como para estudiantes, en tanto les permite participar en red con personas de diversas partes del mundo, intercambiar experiencias e información y publicar trabajos en revistas electrónicas. Por ello, los docentes no podemos permanecer ajenos a los avances del mundo cibernético. Ante este panorama surgen nuevos interrogantes: ¿Cuál es el nivel de acceso y familiaridad de los niños y jóvenes con las Tics?, ¿qué percepción tienen de su uso y de su posicionamiento en la realidad económica, política, social y cultural que vivimos?, ¿qué uso dan a las tics en su vida familiar, escolar y social? y ¿qué conciencia tienen del uso oral, lector y escritor que media en su acercamiento a las Tics? Ó

\section{Bibliografía}

Abascal Vicente, M. D. (1993), Hablar y escuchar una propuesta para la expresión oral en la enseñanza secundaria, Barcelona, Octaedro.

- (2004), La teoría de la oralidad, Málaga, Universidad de Málaga.

Barrera, J. (2007, junio 19), Diario n. ${ }^{\circ} 19$ [profesor practicante: Jairo Barrera].

Calsamiglia, H. y Tusón, A. (2002), Las cosas del decir, Barcelona, Ariel.

Cassany, D. (2006), Tras las lineas. Sobre la lectura contemporánea, Barcelona, Anagrama.

Contreras Islas, I. (2005), "De la oralidad a los videojuegos: la promesa de las narraciones orales en la competencia estética del infante”, en AlterTexto, vol. 3, núm. 6, Universidad Iberoamericana, pp 37-46.

Fairclough, N. (2003), "El análisis crítico del discurso como método para la investigación en ciencias sociales", en Wodak, R. y Meyer, M. (comps.), Métodos de análisis crítico del discurso, Barcelona, Gedisa, pp. 179-204.

García, M. y Quintana, H. (2004, septiembre), "Internet: Herramienta indispensable para enseñar lectura y escritura", en Lectura $y$ vida, año 25.

Grice, H. P. (1991), Las intenciones y el significado del hablante, en Valdés Villanueva, L. (ed.), La Búsqueda del significado. Lecturas de filosofia del lenguaje, Murcia, Universidad Tecnos, pp. 481-510.

Jaimes Carvajal, G. (2003), "Diálogo, dialogismo e interlocución", en Enunciación, núm. 8, Bogotá, Universidad Distrital Francisco José de Caldas, pp. 20-26.

Jonassen, D.; Strobel, J. y Gottdenker, J. (2005), "Model Building for Conceptual Change", en Interactive Learning Environments, núm. 13 , pp. 15-37.

Pardo Abril, N. (2007), Cómo hacer análisis critico del discurso, Santiago de Chile, Frasis.

Perelman, F. et al. (2007, marzo), "Búsqueda en Internet en situaciones de estudio. Los sentidos que construyen los alumnos", en Lectura y vida, año 28, pp. 16-23.

Rodríguez Luna, M. E. (2006), "Consideraciones sobre el discurso oral en el aula", en Enuncia- 
ción, núm. 11, Bogotá, Universidad Distrital Francisco José de Caldas, pp. 59-72.

Rueda Ortiz, R. (2007), "La formación inicial de docentes y la cultura académica", en $\mathrm{Ob}$ servatorio de Informática Educativa, Bogotá, Alcaldía Mayor de Bogotá-Secretaría de Educación, pp. 149-161.

Searle, J. (1969), Actos de babla, Barcelona, Planeta-Agostini.

Soler, S. (2005), Racismo y discurso en los textos escolares. La representación de la diversidad étnica en los textos escolares de ciencias sociales en Colombia [trabajo inédito].

Splitter, L. y Sharp, A. (1995), "La dinámica de la comunidad de indagación", en La otra educación. Filosofía para niños y la comunidad de indagación, Buenos Aires, Manantial.

Testa, M. (1996), Saber en salud. La construcción del conocimiento, Buenos Aires, Lugar Editorial S.A. van Dijk, T. (comp.) (2001a), "El discurso como interacción en la sociedad", en $\mathrm{El}$ discurso como interacción social,,Barcelona, Gedisa, pp.19-66.

- (comp.) (2001b), El discurso como estructura y proceso, Barcelona, Gedisa.

- (2003), "La multidisciplinariedad del análisis crítico del discurso un alegato a favor de la diversidad", en Wodak, R. y Meyer, M. (comps.), Métodos de análisis crítico del discurso, Barcelona, Gedisa, pp. 143-177.

Van Leeuwen, T. (1996), "The Representations of Social Actors", en Coulthard, C. y M., Text and Practices: Reading in Critical Discourse Analysis, Londres, Routledge.

Vasilachis De Gialdino, I. (1997), "Prensa escrita y discurso político: ¿Convergencia o divergencia discursivas?", en La construcción de representaciones sociales: el discurso político y la prensa escrita, Barcelona, Gedisa. 